\title{
Antipsychotic discontinuation syndrome following risperidone withdrawal: a case report from rural India
}

\author{
Sravanti L. Sanivarapu*, Krishnamurthy CN
}

Department of Psychiatry, PES

IMSR, Kuppam - 517425,

Andhra Pradesh, India

Received: 7 November 2013

Accepted: 9 December 2013

*Correspondence to:

Dr. Sravanti L. Sanivarapu,

Email: drsravanti@yahoo.com

(C) 2014 Sanivarapu SL et al.

This is an open-access article distributed under the terms of the Creative Commons Attribution Non-Commercial License, which permits unrestricted non-commercial use, distribution, and reproduction in any medium, provided the original work is properly cited.

\begin{abstract}
Risperidone is an atypical antipsychotic agent used primarily to treat schizophrenia. It is a dopamine antagonist with antiserotonergic, antihistaminergic and antiadrenergic properties. Antipsychotic discontinuation symptoms have been described in the literature following abrupt or rapid reduction in the dose. This unusual case demonstrates that sudden withdrawal of even a modest dose of risperidone may cause significant discontinuation symptoms in susceptible individuals. Hence, there is a need for caution while taking a patient off antipsychotic medications in view of the vulnerable subgroup.
\end{abstract}

Keywords: Antipsychotic discontinuation syndrome, Risperidone withdrawal symptoms

\section{INTRODUCTION}

Literature supports evidence of a set of symptoms characteristic of sudden reduction or withdrawal of antipsychotic medication. Other consequences of withdrawal have been described, including a rapid onset psychosis, sometimes called hypersensitivity or supersensitivity psychosis.,

Case reports describe tics and withdrawal-emergent dyskinesia with risperidone ${ }^{5}$ and supersensitivity psychosis and a cholinergic/serotonergic syndrome with olanzapine. ${ }^{1,6}$ Anecdotal reports suggest that abrupt discontinuation of quetiapine can cause nausea, emesis, lightheadedness, diaphoresis, orthostasis, tachycardia, and nervousness. ${ }^{7,8}$ Although discontinuation syndromes have not been reported with ziprasidone or aripiprazole, tapering any atypical antipsychotic during discontinuation is prudent. Slow down-titration over 6-
8 wks has been recommended especially while switching to a new antipsychotic to prevent such adverse effects.

\section{CASE REPORT}

A 50 year old man presented to the out-patient department with insomnia, bizarre movements, diaphoresis and headache for 3 days. On exploring further he had symptoms suggestive of depression such as low mood, anhedonia, easy fatigability, reduced selfesteem and difficulty concentrating on task at hand for 45 months, with history of two similar episodes in the past and he was on maintenance treatment with fluoxetine (40mg od), risperidone (4mg od) and trihexyphenidyl ( $2 \mathrm{mg}$ bid). He discontinued risperidone 4 days prior to his consultation. No history of death wishes, suicidal ideas. No history suggestive of mania, psychosis or organicity and no significant family history was noted. Treatment details of the previous episodes were not available. Interepisode recovery was complete. The patient was restless, 
sweating excessively and had abnormal choreiform movements. Neurological examination revealed normal findings and no psychopathology was elicitable. Routine blood and urine investigations and CT scan brain were all within normal limits.

Within two days of reinstituting risperidone he reported $50 \%$ improvement in his symptoms and complete resolution of his hyperkinetic movement within about 2 weeks. In his subsequent visit, he reported he was on regular treatment as advised and all his symptoms subsided except for occasional sleep disturbance. The temporal relation between discontinuing risperidone and appearance of his symptoms and subsidence with reinstating the drug, suggest the role of risperidone withdrawal in causing the syndromal presentation.

\section{DISCUSSION}

Risperidone is a dopamine $\mathrm{D}_{2}$, serotonin 5- $\mathrm{HT}_{1 \mathrm{~A}}$, and histamine H1 receptor antagonist. Dopamine, serotonin, and histamine receptors are present in the chemoreceptor trigger zone and brainstem nuclei, the brain regions that on stimulation could cause nausea, emesis and autonomic dysregulation respectively. There is increased receptor binding sites and increased dopamine receptor affinity following chronic dopamine blockade., ${ }^{910}$ And the increased receptor binding sites and affinity may cause hypersensitivity to normalizing dopamine levels following cessation of antipsychotic treatment.

Discontinuation of antipsychotics is known to cause withdrawal symptoms which include sleeplessness for several days, nausea, emesis, lightheadedness, diaphoresis, dyskinesia, orthostatic hypotension, tachycardia, nervousness, dizziness, headache, excessive non-stop crying, and anxiety. $1,2,7,8$

Our patient, who had a long-standing recurrent depressive disorder, was on $4 \mathrm{mg}$ of risperidone as an augmenting agent. He was off risperidone for 4 days and he experienced headache, anxiety, diaphoresis and tachycardia, along with bizarre abnormal hyperkinetic movements, which were predominantly choreiform in nature. These symptoms completely resolved when risperidone was restarted. Temporal relationship between the appearance of symptoms and abrupt withdrawal of risperidone, and resolution of symptoms with reintroduction of risperidone are in favor of risperidone withdrawal syndrome.

Risperidone affects predominantly histamine at low doses, suggests that $\mathrm{Mr}$ A's symptoms were due to withdrawal of $\mathrm{H} 1$ antagonism.

\section{CONCLUSION}

It is well established that antipsychotic drugs are associated with a physiological discontinuation syndrome. Risperidone, being one of the atypical antipsychotics is often used in the treatment of various psychiatric disorders, either as a primary agent or as an augmenting strategy. It is safe to withdraw it gradually, when indicated, to prevent symptoms due to its sudden discontinuation and ensure successful weaning. It is necessary to psychoeducate the family members of the risk of development of withdrawal symptoms on sudden withdrawal.

\section{Funding: No funding sources \\ Conflict of interest: None declared \\ Ethical approval: Not required}

\section{REFERENCES}

1. Nayudu SK, Scheftner WA. Case report of withdrawal syndrome after olanzapine discontinuation. J Clin Psychopharmacol. 2000;20(4):489-90.

2. Tranter R, Healy D. Neuroleptic discontinuation syndromes. J Psychopharmacol. 1998;12(4):401-6.

3. Moncrieff J. Does antipsychotic withdrawal provoke psychosis? Review of the literature on rapid onset psychosis (supersensitivity psychosis) and withdrawal-related relapse. Acta Psychiatr Scand. 2006;114: 3-13.

4. Franks MA, Macritchie KAN, Young AH. The consequences of suddenly stopping psychotropic medication in bipolar disorder. Bipolar Disorders. 2005;4:11-7.

5. Rosebush PI, Kennedy K, Dalton B, Mazurek MF. Pr otracted akathisia after risperidone withdrawal. Am J Psychiatry. 1997;154(3):437-8.

6. Llorca PM, Vaiva G, Lancon C. Supersensitivity psychosis in patients with schizophrenia after sudden olanzapine withdrawal. Can J Psychiatry. 2001;46(1):87-8.

7. Kim DR, Staab JP. Quetiapine discontinuation syndrome. Am J Psychiatry. 2005;162(5):1020.

8. Michaelides C, Thakore-James M, Durso R. Reversible withdrawal dyskinesia associated with quetiapine. Mov Disord. 2005Jun;20(6):769-70.

9. Burt DR, Creese I, Snyder SH. Antischizophrenic drugs: chronic treatment elevates dopamine receptor binding in brain. Science. 1977;196(4287):326-8.

10. Hitri A, Weiner WJ, Borison RL, Diamond BI, Nausieda PA, Klawans HL. Dopamine binding following prolonged haloperidol pretreatment. Ann Neurol. 1978;3(2):134-40.

doi:10.5455/2319-2003.ijbcp20140241

Cite this article as: Sanivarapu SL, Krishnamurthy $\mathrm{CN}$. Antipsychotic discontinuation syndrome following risperidone withdrawal: case report from rural India. Int J Basic Clin Pharmacol 2014;3:233-4. 